\title{
Vivendo sob os murmúrios de Atlas
}

\author{
Francisco Beltrame Trento
}

\section{LUDUEÑA, Fabián.}

La ascensión de Atlas.

Glosas sobre Aby Warburg.

Buenos Aires: Mino y Davila

Editorial, 103 p., 2017.

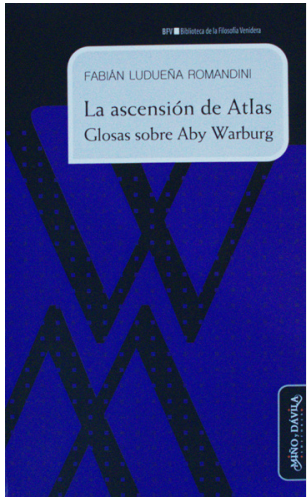

Resumo: Em La Ascensíon de Atlas, Fabian Ludueña discute a obra de Aby Warburg, pensando-a como uma demonologia da contemporaneidade midiática. Além disso, pensa seu atlas imagético, a Mnemosyne, como, em termos lacanianos, o sinthome de Warburg, após os anos que passara na clínica psiquiátrica de Ludwig Biswanger. Continuando seu trabalho de pesquisa na filosofia antiga, segue nessa obra, paralela aos seus dois tratados sobre espectrologia, discutindo como a construção do que consideramos humano acabou por descartar - ou disfarçar nos discursos - quase toda entidade que não se enquadre na normopatia patológica construída pelo que ele denomina a máquina antropotécnica (LUDUEÑA, 2012, 2016). Para tanto, além dos filósofos antigos, discute também questões sobre imagem e subjetividade e, em diálogo com Roland Barthes e Alfred Gell, a re-emergência de mitos e gestos.

Palavras-chave: Aby Warburg; Mnemosyne; imagem; Fabián Ludueña; espectro.

Abstract: Living under Atlas's whispers - In La Ascensíon de Atlas, Fabián Ludueña aims to discuss Aby Warburg's work, thinking of it as a demonology of the contemporary mediatic times. Moreover, he thinks Warburg's imagetic atlas, the Mnemosyne, in lacanian terms: Warburg's sinthome (after those years which Warburg had spent at Ludwig Biswanger's psychiatric clinic.). Ludueña followed his research on antique philosophy and on Mnemosyne. At the same time, and in 
parallel he follows his own two treatises on spectrology. He points out how the construction, which is called 'the human being', ended up discarding, or has been disguised in discursivity, almost any entity that does not fit the pathological normopathy constructed, to what he calls the anthropotechnique machine (LUDUEÑA, 2012, 2016). Beyond ancient philosophers, the author reflects, also, issues of image and subjectivity. In dialoguing with Roland Barthes and Alfred Gell, his concern is about the re-emergence of myths and gestures.

Keywords: Aby Warburg; Mnemosyne; image; Fabian Ludueña; spectrology.

Desde o fim da última década, o filósofo Fabián Ludueña Romandini vem desenvolvendo, em duas grandes obras, A comunidade dos espectros I: antropotecnia, publicada na Argentina em 2010 e aqui traduzida em 2012 pela Editora Cultura \& Barbárie, e Princípios de espectrología: La comunidade de los espectros II, um tratado sobre a emergência da figura antropotécnica. Em outras palavras, o homem moderno normatizado, instaurado como entidade quase transcendental e possuidora de agência absoluta em relação aos outros entes, vivos ou não. Se Giorgio Agamben fala de uma máquina antropológica, Ludueña pensa na antropotecnia, não por questões egóicas e estilísticas, mas para incluir na exclusão novas nuances para além da díade homem/ animal. Tais nuances são as entidades espectrais e incorporais.

Tarefa que já foi muito bem acompanhada pelos estudos genealógicos e arqueológicos de Michel Foucault, bem como toda uma gama de autoras e autores que determinaram que a construção discursiva e material denominada "o humano" já está dando seus últimos suspiros, ainda que sufocando consigo o planeta. Diante disso, não faltam discursos que busquem nomear "o novo homem": o "pós-humano", o "super-homem", o "homem da singularidade". Muitas vezes esses enunciados acabam sendo apropriados pela lógica do Novo Espírito do Capitalismo, ou aquilo que Michel Foucault já havia denominado como o "empreendedor de si" (cf. TRENTO; HOLTZ, 2017). Ainda que muitas mutações estejam em curso nas tecnologias e modos de organização da humanidade, e não cabe a nós condená-las com um julgamento moral, a crítica de Ludueña (2012) é operativa para que pensemos que a maioria delas ainda está orientada para alimentar a máquina antropotécnica, ou seja, reforçar a posição de sujeito quase transcendental do homem, separado dos outros animais e de quaisquer outros entes. Entretanto, Ludueña toma um caminho interessante na produção dos até então dois volumes de seu tratado de espectrologia, partindo de textos da filosofia antiga grega e romana, e do início da difusão do Cristianismo, quando mantinha, mais do que hoje, características de religião que possui em seus dogmas a presença de algo que se assemelha a um politeísmo - ainda que a gestão da oikonomia dessas entidades tenha conseguido mantê-las de outras maneiras no quadro de entidades hoje consideradas canônicas.

A construção da figura do homem passou por um isolamento e apagamento discursivo de outros entes possuidores de capacidade de agência, ou de participarem 
de um agenciamento, das grandes correntes do pensamento ocidental que norteiam os dispositivos de controle e organização de corpos. Um dos mais "apagados", entretanto, e com maior potencial disruptivo, é a dos espectros, sendo eles as entidades intermediárias entre os humanos e os deuses, e capazes de produzir esse link de comunicação entre eles. Nesse caso, "o limite entre o humano e o animal é completamente borrado e desbordado dialeticamente na figura do espectro, que constitui não somente uma indistinção ontológica entre as espécies, quanto uma condensação de todas as formas possíveis no cosmos" (LUDUEÑA, 2016, p. 78). O espectro, ou os daímons, também manifestavam uma agência dos mortos sobre os vivos, quando, na legislação romana e na Grécia Antiga antes da unificação do Cristianismo, - cujos traços fundaram as principais linhas da Filosofia da Lei moderna - as punições eram determinadas em relação àqueles que haviam sido mortos, "a interpretação espectral é performativa, ou seja, transforma a própria coisa que ela interpreta, alterando tanto as bases quanto as estruturas: o econômico, o familiar, o doméstico, o nacional [...]" (LUDUEÑA, 2012).

Além dos tratados de espectrologia, Ludueña se dedicou a outros pequenos livretos, discutindo a obra de H.P. Lovecraft, por exemplo, e a potência monstruosa de Ctulhu. Aqui trataremos de sua última obra, que não consideramos um estudo paralelo, mas uma continuação de seus estudos espectrológicos, buscando fendas contra o homem produzido pela máquina antropotécnica. Forçando as relações, poderíamos denominar daquilo que Suely Rolnik chama por homem ou paradigma "antropo-falo-ego-logocêntrico". A construção da figura do homem também está com a separação do louco e a definição discursiva dos estados que passaram a ser patologizados.

Em La Ascención de Atlas, Fabián Ludueña afirma que passamos a viver sob a égide do Titã condenado eternamente a segurar o firmamento, dando o nome ao oceano que corre sob seus pés. Vivemos a Era de Atlas (p. 18). Ele narra essa mudança de paradigma com base em alguns fatos dos últimos anos de vida de Aby Warburg, historiador da arte alemão internado na clínica de Kreuzlinger nos anos 1920, aos cuidados de Ludwig Biswanger, ex-colega de Freud e um dos pioneiros da Daseinanálise existencialista. Foi lá onde passou cerca de quatro anos, que desenvolveu seu último projeto, o atlas visual Mnemosyne, que levava o mesmo nome da deusa grega da memória, equivalente de Moneta na mitologia romana. Ludueña ressalta que foi também lá que "Warburg havia transformado a sua própria loucura em uma matriz metodológica que organiza a totalidade de seu trabalho de investigação" (LUDUEÑA, 2017, p. 21). Diagnosticado pelo próprio Biswanger com esquizofrenia severa, por Emil Kräpelin como passivo de um "estado misto maníaco-depressivo" ou por Michaud, décadas depois de sua morte, como um "esquizoide incurável" (idem, p. 22-23), o filósofo argentino ressalta que Warburg foi um marco na passagem de um período que ainda era possível utilizar a loucura, ou outras formas de pensamento não-neurotípicos, como elementos estruturantes de sistemas de pensamento filosóficos; claro que, ainda restando muitas exceções incalculáveis, como Antonin Artaud, 
Warburg percibe su propia locura y la analiza como un fenómeno que sólo puede ser explicado apelando a la dimensión cósmicas de los hechos supuestamente subjetivos. Su propia individualidad se disuelve en una dimensión que puede contemplar la historicidad desde un punto fuera del tiempo (LUDUEÑA, 2017, p. 24).

Para Ludueña, os médicos de Warburg foram aqueles que chegaram de maneira mais próxima da compreensão do que o historiador da arte buscava produzir com sua mnemosyne, atlas que mostrava como certas imagens se transportavam entre tempos e conjunturas. Foi em uma famosa conferência, que referenciava o tempo que havia passado com os nativos Pueblos que ocupavam um território do Novo México, e depois os Hopi, onde presenciou o ritual da Serpente, que Aby Warburg tivera que provar sua sanidade, para uma plateia de médicos e psicanalistas.

Warburg parecia ainda acreditar na existência de uma Denkraum, "a distância sacral apropriada que deveria ser mantida em relação às forças sobre-humanas" (LUDUEÑA, 2017 , p. 28). Segundo seus escritos, tal distância passara a ser ameaçada por conta da invenção do telégrafo, do dirigível, das ferrovias etc. (ibidem). As guerras, por sua vez, só poderiam ter sido provocadas pelos deuses e demônios espectrais, que intervinham no estado de coisas daqui. A Primeira Grande Guerra seria, portanto, uma retaliação pelo desafio promovido pelo homem ao se alçar como ser antropotécnico que visa a transcendência com o uso das invenções supracitadas. "Os deuses em fuga talvez não se ausentem, mas se metamorfoseiam, permanecendo irreconhecíveis e silenciosos, nas imagens do mesmo mundo que sempre habitaram" (LUDUEÑA, 2017, p. 68). Tais demônios, entretanto, podem morrer, e causar um abalo, uma "inarmonia cósmica (ibidem, p. 74) no balanço, na mistura (mixis), conceito referido a Plutarco para definir as relações metaestáveis que sustentam os estados das coisas, um ecossistema da mistura que hoje foi retomado como proposta filosófica por Emanuele Coccia (2017).

\footnotetext{
Si los hombres pueden preocuparse de la defección de los demonios, y, como necesario resultado, reflexionar sobre el albur de la historia universal a partir de este suceso, esto sólo se torna posible si el ecosistema de la physis contiene, efectivamente, una relación estable entre la jerarquía de los démonos y sus contrapartidas humanas (LUDUEÑA, 2017, p. 67).
}

Em obras anteriores, Ludueña $(2012,2016)$ já havia pensado na entidade espectral como elemento operativo para descentralizar a ideia de um sujeito da vontade e possuidor de agência, e não actante em agenciamentos que mudam a todo momento de posição. Para tal, revisita a tradição dos antigos, afirmando que os enunciados e as vozes carregam também as vozes dos espectros que haviam vivido em determinados contextos. Algo de outra maneira discutido por Blanchot ao referir-se aos murmúrios que ecoam no som de toda palavra dita. Retornando aos arquivos da filosofia antiga, Ludueña nos alerta de que 
não somente as guerras, mas toda subjetividade é construída por influências demoníacas que constituem um sujeito metaestável. Todos os nomes, doenças e diagnósticos dados a Warburg, individualizando a clínica em um sujeito que foge da coletividade, não caberiam, e especula-se, não fariam sentido ao próprio Warburg, que, unindo a ontologia imagética que propunha à própria construção como indivíduo, não deveria ser considerado o sujeito de ação de suas "maluquices". "O sujeito da loucura não é o indivíduo que padece a ela, mas sim o demônio que agencia sobre seu corpo" (LUDUEÑA, 2017, p. 29). Warburg, de certa maneira, não buscava "aplicar" um conjunto de mitos para explicar os dispositivos comunicacionais que já incessantemente produziam imagens no início do século XX, mas "cimentar uma demonologia que estivesse à altura da era tecnológica" (LUDUEÑA, 2017, p. 34-35), uma "arqueo-demonologia da Era de Atlas" (ibidem) que faça jus à episteme moderna.

Warburg emerge como um personagem revolucionário, mas que hoje, e já em seu tempo, sofria e sofreria com a normopatia das políticas identitárias, às quais são tão caras as características essencialistas e com pouca mobilidade dos indivíduos. Isso porque, de certa maneira, tal como Artaud e seu já exaustivamente citado corpo sem órgãos, "a loucura de Warburg é a figuração de uma exterioridade que se torna íntima: descreve um estado metafísico do mundo no qual nenhuma individuação é possível, a não ser como intersecção de potências extra-humanas" (LUDUEÑA, 2017, p. 36). Ludueña confessa aproximar Warburg a Alfred Gell, especialmente naquilo que o antropólogo britânico costumava chamar de "personalidade fractal": "dentro do indivíduo, só podemos nos encontrar com outras pessoas, ao mesmo tempo em que a circunscrição do que chamamos "corpo" é impossível de ser delimitada sem a concorrência dos objetos ou acasos de seu entorno, que, antes de produzir uma personalidade, produzem uma agência" (GELL, 1998, p. 222-223 apud LUDUEÑA, 2017). Apoiando-se em Heráclito, o caráter também adquire suas características pelas relações estabelecidas com os afetos incorporais dos daímons:

el daímon no moldes tanto el destino del hombre como indica un horizonte donde la vida se juega en su eticidad última. El daímon no es la culpa que agobia a los hombres sino quien comunica que no existe otra culpa que aquella de transformar un estado del mundo en Fatalidad. En este sentido, el daímon no adopta ninguna forma personal, ni bioantropomórfica, ni atrófica, es el nombre, en su enunciación abstracta, del lugar donde el cosmos se torna la experiencia más próxima de Homo e donde la vivencia de lo infinito existente encuentra su estación intermedia hacia los cuerpos. Constituye, por tanto, la sede vacante donde el individuo encuentra al sujeto extático de un sí mismo que siempre se declina en la morfología de lo Otro interior. (LUDUEÑA, 2017, p. 59)

A organização de seu atlas de imagens, seria, especula-se, fruto de seu delírio, de que era possível conhecer a memória do cosmos (LUDUEÑA, 2017, p. 39), e a lógica que faz com que as pranchetas seriam organizadas por sua cartografia do outside, 
uma visão privilegiada sub specie aeternitatis, aquilo que Spinoza denomina como seu terceiro gênero de conhecimento, à imagem de Deus (ou Natureza), ou o conhecimento de todas as redes de relações que constituem os agenciamentos, no tempo acontecimental. Warburg não teria "ficado louco por uma 'empatia' excessiva com seus materiais de arquivo, mas sim por sua crença nas entidades autônomas demenciais que creria persegui-lo" (ibidem, p. 42). A construção da Mnemosyne, sua obra, escrita em imagens seria o que Lacan denomina o sinthome de Warburg (ibidem) ou nada menos do que uma prática clínica. Vale lembrar que aqui não trabalhamos com um julgamento moral de seu estado mental, nem tampouco fazendo um "elogio à loucura", crítica comumente enunciada às obras pós-estruturalistas, mas advogando em favor de uma neurodiversidade possível, ou a mistura de sujeitos inseridos em ontologias e epistemologias distintas e contínuas, não condensáveis em identidades estáticas.

Segundo a obra que comentamos, Warburg simboliza o "último demens da metafísica da presença" (LUDUEÑA, 2017, p. 55); saber delirante, em contrapartida aos inúmeros esforços realistas da filosofia e história da arte contemporânea, inclusive de formas mais recentes em voga, levemente alfinetadas por Ludueña:

\begin{abstract}
El efecto de verdad, no obstante, debe ser buscado con ahínco por la filosofía precisamente por tener una posición óptima para ello en tanto saber delirante y, de esta forma, carente de todo meta lenguaje que aparte al lógos del mundo que describe. Pretender lo contrario, como la hacen ciertas formas del realismo contemporáneo, significa convertirse en el sucedáneo de una inveterada escisión metafísica que se ilusiona con encontrar una exterioridad pura, libre y sensata, donde el pensar ya no sea acosado por el de-lirare (p. 54)
\end{abstract}

Ludueña (2017, p. 69) ainda discute possíveis intersecções entre Warburg, Barthes e Michel Foucault. Cutucando certos teóricos da arte de cunho elitista, afirma que Warburg não havia se interessado apenas por imagens renascentistas, mas qualquer uma. Barthes também fez um trabalho sobre a reemergência do mito na cultura.

Ludueña vê um indício, que, segundo ele, não é mera especulação, de que o conceito de governamentalidade do mundo neoliberal de Michel Foucault, tenha sido semeado de alguma maneira por Barthes em Mitologias. "A governamentalidade sela o pacto da nova aliança, onde só resta lugar para os rituais, vistos mil vezes" (BARTHES, 1957, p. 139 apud LUDUEÑA, 2017, p. 71). Vale lembrar que os gestos têm uma grande importância na obra de Warburg, em especial certos movimentos e padrões cuja repetição percebeu em obras da Renascença e em danças. Ludueña, entretanto, diz que, contra Barthes, Warburg não cai na armadilha de uma ilusão ideológica, observando os mitos não como formas sem conteúdo (LUDUEÑA, 2017, p. 71), carregando uma aura misteriosa das lendas dionisíacas; em seu conceito de Pathosformel (fórmula de páthos), possuidora de uma Nachleben (pós-vida), "de camadas profundas da história e atuam como um dínamo que 
gera energia ao amplificar sentidos e sentimentos soterrados" (BAITELLO, 2014, p. 211), sendo um dos principais equívocos a análise das imagens como entidades que se contêm nelas mesmas, como arquivos mortos, separadas dos afetos que produzem:

Em contextos da história da arte é tradicional pensar as imagens como transições entre os afetos e os arquivos de uma maneira ainda mais predominante. O entendimento de Aby Warburg a respeito das imagens como combinação de afeto e arquivo é o paradoxo efetivo que ele sustenta em seu conceito de Pathosformel pictórico. (KJÆR, 2017, p. 7; tradução nossa) ${ }^{1}$

Dessa maneira, podemos observar como há uma divergência de Ludueña em suas interpretações de Warburg, como, por exemplo, das desenvolvidas por Georges DidiHuberman: "A imagem nunca é signo de si mesma, mas sim das disjunções que sutura, e, portanto, os reinos se atemorizam com a entrada desta ama, ainda sem saber que se trata de uma deusa". (LUDUEÑA, 2017, p. 75). Ou:

Las imágenes del Atlas contemporáneo - desde la publicidad hasta las plataformas Ilamadas sociales - no despiertan angustia por su plenitud de mundo sino porque son la signatura de una ausencia que sacude los cuerpos: no hay efecto de "posesión" como temía Warburg, sino más bien un sacudimiento que testimonia por un abandono, una des-posesión demoníaca. Cuando no se reconoce na imagen la disyunción que la habita, los cuerpos responden con un páthos aterrador (la correlación warburguiana) (LUDUEÑA, 2017, p. 76)

Perdido sob Atlas, o homem está no abismo entre os demônios e humanos, escorregando do contato entre si mesmo e as entidades. Resta a ele, em tempos de Antropoceno, aceitar seu lugar de volta em uma metafísica da mistura e não de sujeito de ação, ou da mixis de Plutarco. Vale lembrar que, querendo ou não, não estamos apenas sob Atlas, mas cada vez mais próximos da queda do céu.

Seus aviões vão se despedaçar nas árvores grandes. A terra vai se encharcar e começar a apodrecer. Depois será pouco a pouco coberta pelas águas, e os humanos vão virar outros, como aconteceu no primeiro tempo. (KOPENAWA, 2015, p.493)

Francisco Beltrame Trento é doutorando no PEPGCOS/ PUC-SP, Comunicação e Semiótica da PUC-SP.

francisco.trento@gmail.com

1 Do original, em dinamarquês: I kunsthistoriske sammenhænge er traditioner for at tænke billedet som overgange mellem affekt og arkiv endnu mere fremtræedende. Aby Warburgs forståelse af billedet som en kombination af affekt og arkiv i det effektive paradoks, han holdt sammen i sit begreb om den billedlige 'Pathosformel' (KJÆR, 2017, p. 7). 


\section{Referências:}

BAITELLO JR, N. "Imagem e emoção: movimentos interiores e exteriores". In: BAITELLO JR, N.;

WULF, C. Emoção e imaginação: sentidos e as imagens em movimento. São Paulo: Estação das Letras e Cores, 2014a.

COCCIA, E. La vie des plantes: une métaphysique du mélange. Paris: Rivages, 2017.

DERRIDA, J. Espectros de Marx. Rio de Janeiro, Relume-Dumará, 1994.

KJÆR, M. Synliggørelser: Det moderne billede i krydsfeltet mellem affekt og arkiv. Copenhagen: Københavns Universitet, Det Humanistiske Fakultet, 2017.

KOPENAWA, D.; ALBERT, B. A queda do céu: palavras de um xamã yanomami. São Paulo: Companhia das Letras, 2015.

LUDUEÑA, F. A comunidade dos espectros: I. antropotecnia. Florianópolis: Cultura e Barbárie, 2012.

. Princípios de espectrología. La comunidad de los espectros II. Buenos Aires: Mino y Davila Editorial, 2016.

La ascensión de Atlas. Glosas sobre Aby Warburg. Buenos Aires: Mino y Davila Editorial, 2017.

TRENTO, F.; HOLTZ, A. C. "BORA PRA ACTION: Análise sobre o discurso do empreendedor de alta performance e o self quantificado". In: XXVI Encontro Anual da Compós, 2017, São Paulo. Anais do XXVI Encontro Anual da Compós, 2017. p. 1-20.

WARBURG, A. Werke in einem Band. Berlin: Suhrkamp Verlag, 2010. 